the Library of Congress schedules. Outside of the scope of the study, apparently, was the development of more recent classifications, although attention is given to the work of Dewey, Cutter, and others. Classifications subsequent to the L.C. are not discussed, although Bliss and Ranganathan are mentioned. In respect to the future, it would appear that the law librarians of the country should be clamoring for the Library of Congress to complete the $\mathrm{K}$ classification, even though it may not be (and cannot be) perfect. Systematic arrangement of materials still appears to make sense in terms of economy of use by both staff and clientele. LaMontagne properly suggests that perfection in classification is hard to come by, and that "A rude shed provides better protection from the elements than the blueprints of a mansion." One point is clear; enough American libraries have committed themselves to the L.C. classification that they depend on the national library to keep it going and up-todate.-Maurice F. Tauber, Columbia University.

\section{THE SATURDAY REVIEW SAYS:} "A great and needed work..." THE

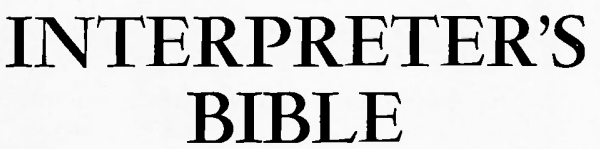

One of the most popular, most comprehensive commentaries available today. Double text, exegesis, exposition all on the Working Page; plus Introductions, exhaustive General Articles, maps, charts and photographic illustrations.

Each volume, $\$ \mathbf{8 . 7 5}$

\section{ABINGDON PRESS NASHVILLE 2, TENNESSEE}

In Canada: G. R. Welch Company, Ltd., Toronto In Australasia: Thomas C. Lothian, Melbourne

\section{Library Surveys}

College and University Library Surveys 19381952. By E. Walfred Erickson. Chicago: ALA, 1961. (ACRL Monograph Number 25). 115 p. $\$ 3.25$.

This survey of surveys provides a brief statement of the history of the device, describes the scope and limitations of surveys in general, and provides some analysis of recommendations made in a dozen surveys conducted between 1938 and 1951 out of nineteen cited in Library Literature through 1952. The analysis covered 775 recommenda. tions and attempted to "ascertain to what extent those recommendations have been carried out, when they were achieved, what the influence of the surveys was, and whether the librarians agreed upon the recommendations."

As far as the analysis went, it accomplished the limited objectives the author set for himself in his doctoral dissertation on which this monograph is based. In a sense this is the report of a post-mortem examination, with no attention paid to the animating spirit which inspired each of the surveys, infused it during its operation, and which was responsible in part for the successes and failures recorded. The concentration on tabulation of results led the author both to give a misleading appearance of precision in the results so carefully tabulated, and to understate the values of social and political pressures which lead to correction of deficiencies to which surveys are intended to call attention.

It is to be hoped that some imaginative colleague with a real interest in the value of surveys will take on where Mr. Erickson left off and will examine the twelve surveys covered by this monograph, as well as others, in the light of the unstated objectives of the surveys, of the methods of persuasion used to effect changes, and of the resulting changes in the library climate of the institutions affected. Admittedly this approach is difficult, but the results of such a study would constitute a valuable sociological document at least as persuasive as Mr. Erickson's tabulations.Marion A. Milczewski, University of Washington Libraries. 